\title{
Qualidade de resistência de peles de codorna curtidas com sais de cromo
}

\author{
Resistance quality of quail skins tanned with chromium salts \\ Calidad de resistencia de las pieles de codorniz curtidas con sales de cromo
}

Giorgia Kesley Marques dos Santos ORCID: https://orcid.org/0000-0001-5238-6396

Centro Universitário Ingá, Brasil

E-mail: gkmarques.22@gmail.com

Gislaine Gonçalves Oliveira

ORCID: https://orcid.org/0000-0002-7819-3493

Universidade Estadual de Maringá, Brasil

E-mail: gislaine_oliveira14@hotmail.com

Sabrina Campos Sbaraini

ORCID: https://orcid.org/0000-0002-7165-6563

Universidade Estadual de Maringá, Brasil

Email:sabrinacsbaraini@gmail.com

Simara Márcia Marcato

ORCID: https://orcid.org/0000-0003-4559-4183

Universidade Estadual de Maringá, Brasil

E-mail: smmarcato@uem.br

Maria Tereza Frageri Paulino

ORCID: https://orcid.org/0000-0001-9616-7697

Universidade Estadual de Maringá, Brasil

E-mail: mariaterezafrageri@hotmail.com

Simone Siemer

ORCID: https://orcid.org/0000-0002-9052-5841

Universidade Estadual de Maringá, Brasil

E-mail: si_syemer@hotmail.com

Jaisa Casetta

ORCID: https://orcid.org/0000-0001-9994-077X Universidade Estadual de Maringá, Brasil

E-mail: jaisacasettta@hotmail.com

Marcos Antonio Matiucci

ORCID: https://orcid.org/0000-0003-2053-2672 Universidade Estadual de Maringá, Brasil

E-mail: m.matiucci@hotmail.com

Josiane Aparecida Volpato

ORCID: https://orcid.org/0000-0002-6721-2388

Universidade Federal da Grande Dourados, Brasil

E-mail: josyvolpato@yahoo.com.br aine_oliveira14@hotmail.com

Andresa Carla Feihrmann

ORCID: https://orcid.org/0000-0003-2389-0467

Universidade Estadual de Maringá, Brasil

E-mail: andresafeihrmann@gmail.com

Maria Luiza Rodrigues de Souza

ORCID: https://orcid.org/0000-0001-5643-0841

Universidade Estadual de Maringá, Brasil

E-mail:mlrsouza@uem.br

\section{Resumo}

A pele de codorna não é levada em consideração por ser muito pequena e aparentemente frágil, mas com o curtimento pode aumentar a sua resistência e agregar um bom valor quando utilizada em determinados produtos. Também, após o curtimento, pelo fato de ser um couro fino e com certa elasticidade, ele pode ser destinado a aplicações de detalhes em confecções de vestuários, calçados, bolsas, bijouterias finas ou mesmo acessórios diversos. Este trabalho teve como objetivo avaliar a resistência da pele de codorna tipo postura (Coturnix coturnix japonica) após processo de curtimento. As peles foram submetidas às etapas remolho, caleiro, desencalagem, purga, desengraxe, piquel, curtimento, neutralização, recurtimento e tingimento, engraxe, fixação, secagem e amaciamento. Após todo o processo de curtimento foram retirados os corpos de prova para os testes de resistência (rasgamento progressivo, tração e alongamento). O couro de codorna apresentou uma espessura variando de 0,38 a $0,42 \mathrm{~mm}$, cuja resistência ao rasgamento progressivo foi de $4,11 \mathrm{~N} / \mathrm{mm}$, de determinação da tração de 2,56 N/mm2 e alongamento de 39,1\%. Os couros de codorna após curtimento com sais de cromo, apresentou uma delgada espessura e baixíssima resistência ao 
rasgamento progressivo e tração, assim com baixa elasticidade. Portanto, um couro frágil para aplicação em vestuário, apesar da possibilidade de uso em pequenos acessórios ou em alguns tipos de artefatos.

Palavras-chave: Coturnix coturnix japonica; Rasgamento progressivo; Resíduos de abate; Tração e alongamento.

\begin{abstract}
Quail skin is not taken into account because it is very small and apparently fragile, but with tanning it can increase its resistance and add good value when used in certain products. Also, after tanning, as it is a fine leather with a certain elasticity, it can be used for detail applications in garments, shoes, bags, fine jewelry or even various accessories. This study aimed to evaluate the skin resistance of posture-type quail (Coturnix coturnix japonica) after a tanning process. The hides were submitted to soaking, lime, deliming, purging, degreasing, piquel, tanning, neutralization, retanning and dyeing, grease, fixation, drying and softening steps. After the entire tanning process, the specimens were removed for strength tests (progressive tearing, traction and elongation). The quail hide had a thickness ranging from 0.38 to $0.42 \mathrm{~mm}$, whose progressive tear strength was $4.11 \mathrm{~N} / \mathrm{mm}$, with a tensile determination of $2.56 \mathrm{~N} / \mathrm{mm} 2$ and elongation of $39.1 \%$. Quail hides, after tanning with chromium salts, presented a thin thickness and very low resistance to progressive tearing and traction, as well as low elasticity. Therefore, a fragile leather for application in clothing, despite the possibility of use in small accessories or some types of artifacts.
\end{abstract}

Keywords: Coturnix coturnix japonica; Progressive tearing; Slaughter residues; Traction and elongation.

\title{
Resumen
}

No se tiene en cuenta la piel de codorniz porque es muy pequeña y aparentemente frágil, pero con el bronceado puede aumentar su resistencia y aportar un buen valor cuando se utiliza en determinados productos. Además, después del curtido, al ser una piel fina con cierta elasticidad, se puede utilizar para aplicaciones de detalle en prendas, zapatos, bolsos, bisutería o incluso diversos complementos. Este estudio tuvo como objetivo evaluar la resistencia de la piel de la codorniz postural (Coturnix coturnix japonica) después de un proceso de bronceado. Las pieles se sometieron a las etapas de remojo, cal, desengrasado, purgado, desengrasado, piquel, curtido, neutralización, recurtido y teñido, engrasado, fijación, secado y ablandamiento. Tras todo el proceso de curtido, se retiraron las probetas para realizar pruebas de resistencia (desgarro progresivo, tracción y alargamiento). La piel de codorniz tenía un espesor de 0,38 a $0,42 \mathrm{~mm}$, cuya resistencia al desgarro progresivo fue de 4,11 N/ mm, con una determinación de tracción de 2,56 N / mm2 y alargamiento de 39,1\%. Las pieles de codorniz, después del curtido con sales de cromo, presentaron un espesor fino y muy baja resistencia al desgarro progresivo y tracción, así como baja elasticidad. Por tanto, un cuero frágil para aplicación en ropa, a pesar de la posibilidad de uso en pequeños accesorios o algún tipo de artefactos.

Palabras clave: Coturnix coturnix japonica; Desgarro progresivo; Residuos de matanza; Tracción y alargamento.

\section{Introdução}

No Brasil, as codornas foram trazidas por imigrantes italianos e japoneses com interesse inicial pelo seu canto, em 1959. No entanto, com o passar dos anos, tem se especializado em produção de carnes e ovos.

Nos últimos anos a coturnicultura têm apresentado desenvolvimento bastante acentuado, adequando-se as novas tecnologias de produção, onde a atividade tida como de subsistência, passou a ocupar um cenário de atividade altamente tecnificada com resultados promissores aos investidores (Pastore et al., 2012). Em 2018 o plantel de codornas obteve um crescimento e atingiu aproximadamente 16,8 milhões de cabeça, e com isso um aumento de 3,90\%, a produção de ovos obteve um declínio de 2,1\% de acordo com o Instituto Brasileiro de Geografia e Estatística (IBGE, 2019). Vários fatores estão relacionados com o consumo dos ovos desde hábitos e questões sociais (Bertechini, 2010, Marques, 2019).

Todavia, para qualquer atividade se torna importante o aproveitamento integral dos subprodutos. Dentre eles, a pele, as penas, vísceras e pele são descartadas. A pele não é levada em consideração por ser muito pequena e frágil, mas com o curtimento pode aumentar a resistência. Pelo fato de o couro ser fino e com certa elasticidade, ele pode ser destinado a aplicações de detalhes em confecções de vestuários ou mesmo para diversos acessórios. Como forma de agregar um bom valor aos subprodutos, a pele pode ser aproveitada pela indústria de beneficiamento do couro. Após a sua retirada e a conservação de maneira correta até o momento do curtimento, esta poderá se transformar em uma matéria-prima de elevado valor comercial, principalmente pelo seu aspecto visual, devido ao típico desenho formado pelos poros referentes aos folículos pilosos, que acaba despertando a atenção do público em geral (Figura 1).

A pele de certos animais, como coelho, cabras, rãs, pés de galinha e avestruz podem ser beneficiada e resultar em uma matéria-prima com certa qualidade e de aspecto peculiar inimitável após o curtimento. Como por exemplo dos resíduos da 
industrialização, a pele de peixes de escama, após o curtimento apresentam um desenho de flor característicos, devido à inserção e proteção das escamas. Alguns autores afirmam que as peles de peixes são consideradas couro exótico e inovador, com aceitação geral em vários segmentos da confecção (Souza, 2004). Porém, as peles dos animais, atualmente, estão sendo desperdiçadas ou subutilizadas devido à falta de conhecimento das técnicas possíveis para a sua transformação e aplicação na indústria de confecção de vestuários, de calçados ou de artefatos em geral, (Souza et al., 2006). E são peles que muitas vezes proporcionam características especificas de interesse comercial, em função da beleza proporcionada pelo considerado desenho que é expresso na linguagem do curtimento em desenho de flor, considerada a superfície de cada pele animal após curtimento.

A maioria das espécies animais quando abatidas e removidas suas peles, podem ser submetidas ao processo de curtimento para transformá-la em couro, necessitando conhecer a qualidade obtida após curtimento das mesmas, principalmente quando objetiva sua utilização em determinados produtos, que necessita de resistência para sua aplicação. Alguns trabalhos foram desenvolvidos testando a resistência de peles e diferentes agentes curtentes (Souza et al., 2021 a , Souza et al., 2021b, Matiucci et al., 2021, Santos et al., 2021).

Dentre as aves, não temos conhecimento do curtimento da pele de codornas, além disso, falta pesquisas sobre o processo de curtimento das peles destes animais. Onde, não se conhece absolutamente nada sobre a resistência da pele que é extremamente fina antes do processo de curtimento para transformá-la em couro. Apesar do seu pequeno tamanho, mas, em função do seu desenho típico, onde as penas estavam inseridas quando no animal, após o processo de curtimento, com a remoção das mesmas proporciona um bonito desenho (Figura 1), podendo ser utilizada em determinados produtos e artesanatos.

Para o processo de curtimento, a pele é submetida a determinados processos, com utilização de produtos químicos e/ou vegetais, preservando-a da putrefação ocasionada por processos autolíticos ou ataque bacteriano. Assim, a pele é transformada em um material imputrescível, com características de maciez, elasticidade, flexibilidade, resistência à tração, e com especiais qualidades físico-mecânicas, cujo processo é denominado de curtimento (Hoinacki, 1989). Nesse processo de curtimento se mantem a natureza fibrosa da pele, onde as fibras colágenas devem ser previamente separadas para poder remover todo o material interfibrilar, através da ação de produtos químicos. Em seguida, de acordo com Hoinacki et al. (1994) essas fibras colágenas devem ser acidificadas e tratadas com agentes curtentes (taninos vegetais ou sintéticos, minerais, como exemplo o cromo e sulfato de alumínio) para transformarem-na em couros,

Diante disso, objetivou-se nesse trabalho caracterizar a resistência das peles de codorna tipo postura (Coturnix coturnix japonica) submetidas ao processo de curtimento com sais de cromo.

\section{Metodologia}

O experimento foi realizado no Laboratório de Processamento de Peles de peixe e demais Espécies de pequeno e médio porte da Universidade Estadual de Maringá (UEM), localizado na Fazenda Experimental de Iguatemi (FEI).

As peles das codornas japonesas foram obtidas de animais descartados, após o término de postura. As peles com penas e penugem foram utilizadas para o processo de curtimento. Após, foram retiradas o restante das penas delicadamente do animal de forma a preservar sua integridade. As peles foram congeladas até o momento do processo de curtimento.

\section{Processo de curtimento das peles de codorna}

Para o curtimento, as peles foram descongeladas, para tanto, foram colocadas em recipiente com água à temperatura ambiente, para facilitar o descongelamento. As peles ficaram em remolho e não foi realizado o descarne. Foi utilizada a metodologia descrita por Souza (2004) e Hoinachi (1989). Sendo as etapas de Caleiro (3\% cal, 0,5\% tensoativo e $4 \%$ de Dermaphel plus $\left.{ }^{\circledR}\right)$, desencalagem ( $2 \%$, sulfato de amônia, $0,5 \%$ de tensoativo- $0,5 \%, 4 \%$ de Dekalon $\left.{ }^{\circledR}\right)$, purga ( $0,5 \%$ Rohapon 
NPB®, 0,5\%, tensoativo), desencalagem (4\% Dekalon®, 0,5\% tensoativo), desengraxe (0,5\% tensoativo e $10 \%$ querosene), piquel $(95 \mathrm{~g} / \mathrm{L}$ de sal, baumé $7,3 \%$ de ácido fórmico $(\mathrm{pH}=3,0)$, curtimento ( $8 \%$ de Chromosal B®), basificação $(2 \%$ bicarbonato de sódio), neutralização (1\% bicarbonato de sódio e 1\% Branderme $\left.{ }^{2}\right)$, recurtimento e tingimento (3\% Weibull®, $3 \%$ Syntak F®, $1 \%$ Tamol®, 2\%, corante), engraxe (4\% superderma GA®, 4\% superderma GW®), fixação (2\% ácido fórmico), secagem (à sombra) e amaciamento (manual).

\section{Obtenção dos corpos de provas para os testes físico-mecânicos do couro de codorna}

Após o curtimento (Figura 1) das peles, foram retirados os corpos de prova para a realização dos testes de rasgamento progressivo (ABNT-NBR 3376, 2014a) e determinação da tração e alongamento (ABNT-NBR ISSO 3376, 2014b), (Figura 2). Os corpos de provas foram retirados com auxílio do balancim, com facas de corte específicas para cada tipo de teste, para então ser avaliada a resistência do couro no equipamento chamado Dinamômetro.

Foram determinadas as medidas de espessura em locais específicos conforme as normas da ABNT referente à cada tipo de teste a ser realizado. As medidas foram realizadas com auxílio de um espessímetro. Foram retirados 10 corpos de prova no sentido transversal da pele para o teste de tração e alongamento e 10 corpos de prova no sentido transversal para a determinação do rasgamento progressivo.

Figura 1- Couro de codorna após curtimento com sais de cromo. As setas indicam os poros dos foliculos das penas.

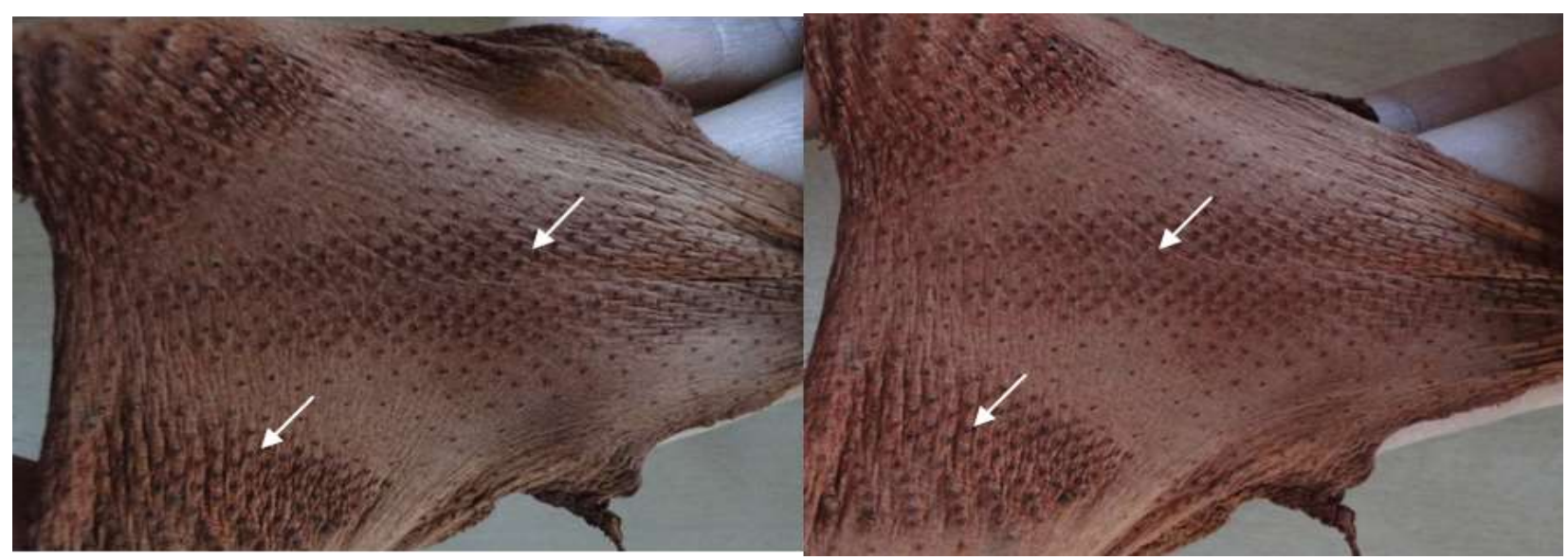

Fonte: Autores.

Os corpos de prova foram retirados dos couros de codorna, com auxílio de um balancim (ABNT - NBR 2418, 2015). Foram determinadas as medidas de espessura (ABNT - NBR 2589,2016) de cada amostra para os cálculos de resistência à tração e alongamento e rasgamento progressivo. Em seguida as amostras foram levadas para um ambiente climatizado em torno de $23 \pm 2^{\circ} \mathrm{C}$ e umidade relativa do ar de $50 \pm 5 \%$, por 24h, conforme (ABNT- NBR 10455, 2021). Para os testes mecânicos (Figura 2) foi utilizado o dinamômetro da marca EMIC, com velocidade de afastamento entre as cargas de $100 \pm 10$ mm/min. A célula de carga utilizada no dinamômetro foi de 200 kgf. A calibração foi realizada pela Emic-Dcame, laboratório de calibração credenciado pela Cgcre/Inmetro sob nº 197. 
Figura 2 - Teste de rasgamento progressivo (A) e teste de tração e alongamento (B) dos corpos de provas dos couros de codorna curtidas com sais de cromo.

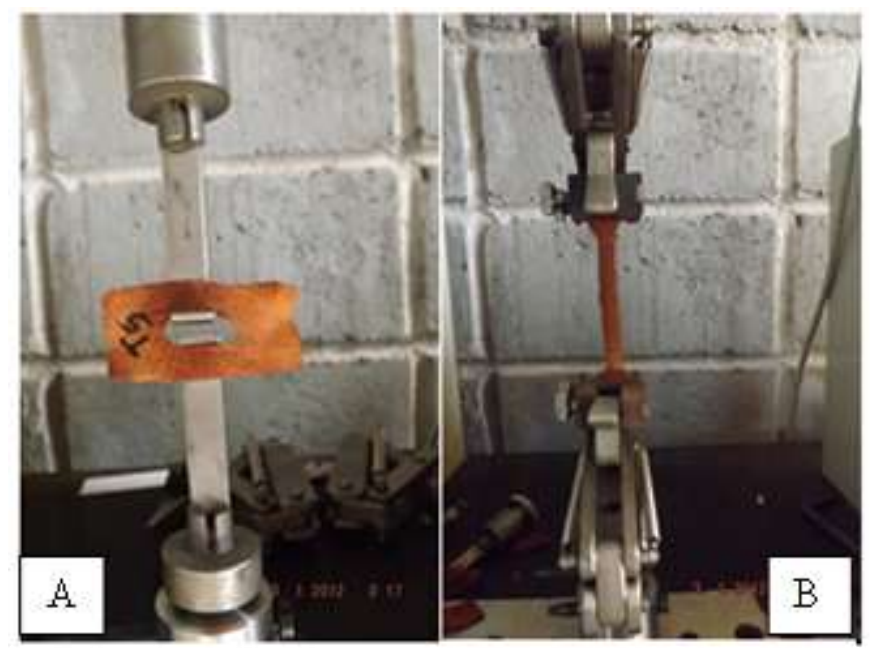

Fonte: Autores.

Não foi realizada análise estatística para os testes de resistência, apenas foi realizada uma análise descritiva, baseada nos resultados já obtidos para outras espécies de couros.

\section{Resultados e Discussão}

Os couros de codorna apresentaram uma espessura variando de 0,38 a $0,42 \mathrm{~mm}$. Esses couros apresentaram baixa resistência à determinação do rasgamento progressivo, tração e alongamento, cujos valores foram respectivamente, de 4,11 $\mathrm{N} / \mathrm{mm}, 2,56 \mathrm{~N} / \mathrm{mm}^{2}$ e $39,10 \%$ (Tabela 1 ).

Em função da dificuldade de se encontrar resultados sobre a resistência de couros de codorna, foram utilizados resultados de couros de outras espécies animais para fazer uma comparação em termos de resistência dos couros, uma vez que não existe um padrão em resistência para utilização de couro de codorna, segundo normas da ABNT.

O couro do pé de frango estudado por Machado et al. (2013) apresentou uma espessura que variou de 0,65 a 0,96mm, valores muito superiores aos obtidos para o couro de codorna. Os mesmos autores relataram que o couro de pé de frango apresentou uma resistência ao rasgamento progressivo de 20,72 a 25,55 N/mm, de tração de 5,97 a 7,27 N/mm² e alongamento de 32,10 a 35,90\%, em função da técnica de curtimento com diferentes agentes curtentes. Os valores relatados por Machado et al. (2013) foram muito superiores aos obtidos para esse couro de codorna. Mas, se levado em comparação os resultados deste experimento com os obtidos por Machado et al. (2013), pode-se considerar alguns fatores que influenciaram na resistência, tais como: os relacionados a espécie e ao processo de curtimento. Quanto a espécie, foram pele de codorna e pé de frango, os tecidos diferentes (da pele do corpo e da pele do pé e canela), espessuras diferentes e o agente curtente utilizado. Quanto ao tecido, haveria necessidade de fazer a análises histológica, mas tudo indica que a distribuição das fibras colágenas seja diferente em relação a espécies e localização do tecido no corpo do indivíduo. Já a espessura, pode inferir que a quantidade de fibras colágenas sobrepostas são diferentes e consequentemente afetaria a resistência. Quanto ao agente curtente, deveria ser analisado até o uso de diferentes agentes curtente assim como as proporções a serem utilizadas, para poderem agir eficientemente com as fibras colágenas e proporcionar um melhor resultado de resistência ao couro. Estes fatores devem ser considerados na determinação da qualidade de resistência desses tipos de couros. 
Tabela 1 - Análise de determinação do rasgamento progressivo, tração e alongamento dos couros de codorna curtidos com sais de cromo.

\begin{tabular}{cccccccc}
\hline \multicolumn{3}{c}{ Rasgamento Progressivo } & & \multicolumn{3}{c}{ Tração e Alongamento } \\
\cline { 1 - 2 } $\begin{array}{c}\text { Espessura } \\
(\mathrm{mm})\end{array}$ & $\begin{array}{c}\text { Força } \\
\text { máxima } \\
(\mathrm{N})\end{array}$ & $\begin{array}{c}\text { Rasgo } \\
(\mathrm{N} / \mathrm{mm})\end{array}$ & & $\begin{array}{c}\text { Espessura } \\
(\mathrm{mm})\end{array}$ & $\begin{array}{c}\text { Força } \\
\text { máxima } \\
(\mathrm{N})\end{array}$ & $\begin{array}{c}\text { Tração } \\
\left(\mathrm{N} / \mathrm{mm}^{2}\right)\end{array}$ & $\begin{array}{c}\text { Alongamento } \\
(\%)\end{array}$ \\
\hline 0,38 & 1,42 & 4,11 & & 0,42 & 9,90 & 2,56 & 39,10 \\
\hline
\end{tabular}

Médias obtidas a partir de 10 corpos de provas analisados. Fonte: Autores.

Utilizando o mesmo método de curtimento desse trabalho, Franco et al. (2012), avaliaram o curtimento de peles de coelhos com sais de cromo, observaram 0,69 a $0,87 \mathrm{~mm}$ de espessura da peles e relataram que as peles de coelhos (sem pelos) apresentaram maior elasticidade, porém os autores observaram que houve interação dos efeitos (região x sentido do couro) analisados, sendo que os couros de coelhos apresentaram significativamente maior elasticidade no sentido longitudinal da região dorsal $(64,57 \%)$ e na região dos flancos no sentido longitudinal a menor elasticidade $(48,00 \%)$. Também, comparando os resultados de tração dos couros de codorna com os obtidos por Franco et al. (2012), para os couros de coelhos, estes apresentaram maior resistência a tração $(7,98$ a 10,84N/mm2) em relação aos de codorna analisados neste trabalho (Tabela 1).

Todavia, comparando os resultados obtidos por Franco et al. (2012), para os couros (peles sem pelos) de coelhos com os de codorna, para os parâmetros de elasticidade e de tração, os de coelhos apresentaram um maior grau de elasticidade e resistência. Acredita-se que um fator que pode estar influenciando nesses resultados seja forma de distribuição das fibras colágenas, assim como, os percentuais de produtos químicos ou tipos de produtos utilizados no processo de curtimento. Os couros de codornas apresentaram maior resistência a tração $\left(2,56 \mathrm{~N} / \mathrm{mm}^{2}\right)$ que o rúmen-retículo de bovino avaliados por Hoch et al. (2009). Estes autores avaliaram técnicas de recurtimento para rúmen-retículo de bovino, cujos resultados foram de 2,13 $\mathrm{N} / \mathrm{mm}^{2}$ para recurtimento com tanino sintético e $2,05 \mathrm{~N} / \mathrm{mm}^{2}$ para sais de cromo.

Segundo Almeida et al. (2019) avaliando as características físico-químicas, mecânicas do rúmen e retículo de ovinos submetidos a diferentes técnicas de recurtimento, relataram que o rúmen apresentou 0,7 $\mathrm{mm}$ de espessura, 3,61 N/mm2 de tração, 74,09\% de alongamento e 28,39N/mm de rasgamento progressivo e para os retículos os valores foram respectivamente $1,32 \mathrm{~mm}, 2,52 \mathrm{~N} / \mathrm{mm} 2,76,78 \%$ e 17,66 N/mm para as mesmas características estudadas. Independentemente dos resultados relatados por Almeida et al. (2019) para rúmen-retículo de ovinos, para os mesmos parâmetros analisados nos couros de codornas, estes apresentaram menor espessura e resistência a tração e rasgamento progressivo, assim como a elasticidade. Apesar que o valor de tração do retículo ter sido muito semelhante ao de codorna deste trabalho (Tabela 1). Portanto, quando comparado esse tipo de tecido rúmen-reticulo de bovino ou ovino, com o couro de codornas, nota-se que apesar de maior espessura dos rúmenes-retículos, a resistência desse tipo de estrutura foi muito baixa, pois apenas o retículo de ovinos apresentou semelhança aos resultados obtidos para codorna para a tração. Isso pode estar associada à arquitetura histológica dos tecidos avaliados, sendo que para o rúmen-retículo a distribuição das fibras colágenas sejam menos entrelaçadas entre si, proporcionando menor resistência.

Fazendo uma comparação da resistência do couro de codorna com as de peixes, pode se observar que segundo Franco et al. (2013) os couros de tilápia do Nilo apresentaram menor espessura $(0,68 \mathrm{~mm})$, resistência à tração $\left(11,86 \mathrm{~N} / \mathrm{mm}^{2}\right)$, rasgamento progressivo $(40,18 \mathrm{~N} / \mathrm{mm})$, menor elasticidade $(52,63 \%)$, comparada aos couros de pacu e tambaqui. O couro de tambaqui, o de maior espessura $(0,89 \mathrm{~mm})$ entre os três couros de peixes analisados. A resistência para as variáveis analisadas do couro de tambaqui foram de $29,49 \mathrm{~N} / \mathrm{mm}^{2}$ para a tração, $80,01 \mathrm{~N} / \mathrm{mm}$ para o rasgamento progressivo. O couro do pacu apresentou $0,82 \mathrm{~mm}$ de espessura, $18,07 \mathrm{~N} / \mathrm{mm}^{2}$ de tração, 72,50\% de alongamento e 63,72 N/mm de rasgamento progressivo. Pelos resultados observados nota-se que os couros de peixes independente da espécie, apresentam uma maior espessura, 
resistência a tração e alongamento e rasgamento progressivo comparado aos couros de codornas. Nessa situação também a maior resistência do couro do peixe está associada a forma de distribuição das fibras colágenas, pois estas se encontram bem definidas, como camadas sobrepostas paralelamente à superfície da pele e estão entrelaçados, de espaço em espaço, por grossos feixes perpendiculares à superfície (Hoinacki, 1989), proporcionando uma amarração mais eficiente aos feixes de fibras colágenas e com essa diferença entre as espécies de peixes quanto a resistência, também está relacionada a forma de distribuição das fibras, cada espécie apresenta algum tipo de particularidade nessa arquitetura histológica da pele (Souza, 2004). Comparando com o trabalho desenvolvido por Souza et al. (2021 a), onde os autores trabalharam com diferentes categorias de peso ao abate curtidos com sais de cromo, foi obtido valores superiores aos encontrados nesse experimento, os pesos dos animais variaram de $500 \mathrm{~g}-800 \mathrm{~g}$, os couros de tilápia do Nilo apresentaram uma média de espessura $(0,64 \mathrm{~mm})$, resistência a tração $\left(13,27 \mathrm{~N} / \mathrm{mm}^{2}\right)$, rasgamento progressivo $\left(16,55 \mathrm{~N} / \mathrm{mm}^{2}\right)$ e força máxima $(27,19 \mathrm{~N})$.

Portanto, baseado nestes resultados obtidos dos couros de codornas e comparado aos demais couros mencionados, pode-se verificar que é possível transforma a pele de codorna em couro e agregar certa resistência a esse couro, porém está resistência é muito baixa comparada a maioria dos couros já analisados. A resistência desse couro fica apenas próximo dos valores de tração do retículo de ovinos (Almeida et al., 2019) e superior apenas para os resultados obtidos para rúmen e retículo de bovinos, de acordo com os resultados relatados por Hoch et al. (2009).

Através dessa abordagem, ficou claro que a resistência do couro está diretamente relacionada com a espécie animal, a espessura desse tegumento e a própria arquitetura de distribuição das fibras colágenas (Souza et al., 2021 c), sendo a justificativa para tantas variações nos valores de resistência apresentado pelos autores supracitados. Junqueira et al. (1983) também afirmam que o arranjo estrutural das fibras colágenas da derme compacta, bem como a espessura desse estrato, permite que a pele apresente grande resistência às diferentes forças de tração. Mas, não se pode deixar de complementar que existem outros fatores que influenciam o aumento da resistência do couro, ou seja, a técnica empregada no curtimento das peles (tipos de produtos químicos, concentração, tempo de processo), pode proporcionar num couro delgado uma considerável resistência.

Portanto, nas condições da técnica de curtimento deste trabalho, a pele de codornas japonesas pode ser transformada em couro, mas para uso em produtos que necessita de revestimento, para agregar valor, em função de sua beleza. Pode ser utilizado para pulseiras de relógio, braceletes, bijuterias, porta níquel, revestimento de caixas decorativas, entre outros sequentemente maior resistência ao couro.

\section{Conclusão}

Os couros de codorna após curtimento com sais de cromo, apresentou uma delgada espessura e baixíssima resistência ao rasgamento progressivo e tração, assim com baixa elasticidade. Portanto, um couro frágil para aplicação em vestuário, apesar da possibilidade de uso em pequenos acessórios ou em alguns tipos de artefatos. Mais estudos devem ser realizados para avaliar fatores que possam proporcionar um aumento na resistência do couro da espécie de codorna (Coturnix coturnix japonica), assim como a utilização de diferentes agentes curtentes, como diferentes níveis, diferentes metodologias para curtimento, e assim a aplicação em produtos na indústria de couro.

\section{Referências}

ABNT. (2014a). NBR ISO 3376: Couro -Ensaios físicos e mecânicos -determinação da força de rasgamento progressivo. Parte 1: rasgamento de extremidade simples. Associação Brasileira De Normas Técnicas -ABNT. Rio de Janeiro.

ABNT. (2014b). NBR ISSO 3376: Couros - Ensaios físicos e mecânicos - determinação da resistência à tração e percentual de extensão. Rio de Janeiro

ABNT. (2015). NBR 2418: Couro: Cortes de corpos-de-prova. Associação Brasileira de Normas Técnicas-ABNT. Rio de Janeiro.

ABNT. (2016). NBR 2589: Determinação da espessura. Associação Brasileira De Normas Técnicas -ABNT. Rio de Janeiro. 
ABNT. (2020). NBR ISO 10455: couro -Ensaios físicos e mecânicos-climatização de materiais usados na fabricação de calçados e correlatos. Parte 2: rasgamento de extremidade simples. Associação Brasileira De Normas Técnicas -ABNT. Rio de Janeiro.

Almeida Cerquetani, D., Souza, M. L. R., Gasparino, E., Dourado, D. M., da Silva, S. C. C., Roldi, G., ... \& Lala, B. (2019). Physico-chemical, mechanical and histological characteristics on rumen and reticulum of sheep submitted to different techniques of retanning. Medicina Veterinária (UFRPE), 13(1), 102108 .

Bertechini, A.G. (2010). Situação atual e perspectivas para Coturnicultura no Brasil. In: Simpósio Internacional e III Congresso Brasileiro de Coturnicultura. Lavras: AnaisLavras - MG.

Franco, M. L. R. S., Franco, N. P., Gasparino, E., Dorado, D. M., Prado, M., \& Vesco, A. P. D. (2013). Comparação das peles de tilápia do Nilo, pacu e tambaqui: Histologia, composição e resistência. Archivos de zootecnia, 62(237), 21-32.

Franco, M. L. R. S., Prado, M., Domingues, M. C., Gasparino, E., Scapinello, C., \& Silva, S. C. C. (2012). Influência do tempo do proces so de curtimento na qualidade dos couros de coelhos (O. Cunniculus). Archivos de zootecnia, 61(235), 425-435.

Hoch, A. L. V., do Prado, M., de Souza Franco, M. L. R., Scapinello, C., do Prado Franco, N., \& Gasparino, E. (2009). Ação de diferentes agentes curtentes utilizados no curtimento de peles de coelhos: testes físico-mecânicos dos couros. Acta Scientiarum. Animal Sciences, 31(4), 411-415.

Hoinacki, E., \& Gutheil, N. C. (1989). Peles e couros. $2^{\circ}$ edição. SENAI.

Hoinacki, E., Moreira, M. V., \& Kiefer, C. G. (1994). Manual básico de processamento do couro (pp. 356-364). Porto Alegre: SENAI.

IBGE. Instituto Brasileiro de Geografia e Estatística (2019). Ministério da Agricultura, Pecuária e Abastecimento. em:http://www.agricultura.gov.br

Junqueira, L. C. U., Joazeiro, P. P., Montes, G. S., Menezes, N., \& Pereira Filho, M. E. (1983). É possível o aproveitamento industrial da pele dos peixes de couro. Tecnicouro, 5(5), 4-6.

Machado, A. C., do Prado, M., de Souza Franco, M. L. R., Gasparino, E., da Silva, S. C. C., \& Del Vesco, A. P. (2013). Couros de pé de frango curtidos com diferentes agentes curtentes: Teste de resistência. Acta Tecnológica, 7(2), 38-43.

Marques, R. (2019, November 1). Coturnicultura - Uma visão geral. Coturnicultura - Saiba mais sobre ela. Retrieved October 27, 2021, from https://agroceresmultimix.com.br/blog/coturnicultura-uma-visao-gerao/

Matiucci, M. A., Feihrmann, A. C., Oliveira, G. G., Corrêa, S. S., dos Reis Goes, E. S., \& de Souza, M. L. R. (2021). Qualidade de resistência de peles de tilápia e salmão submetidas ao processo de curtimento com tanino vegetal. Research, Society and Development, 10(8), e43910817242-e43910817242.

Pastore, S. M., Oliveira, W. D., \& Muniz, J. C. L. (2012). Panorama da coturnicultura no Brasil. Revista eletrônica nutritime, 9(6), 2041-2049.

Santos, F. V., Martins, G. L., Oliveira, G. G., Sbaraini, S. C., Matiucci, M. A., de Castro, A. C. V. J., ... \& de Souza, M. L. R. (2021). Qualidade de resistência de peles de Tilápia do Nilo submetidas ao curtimento com tanino vegetal. Research, Society and Development, 10(8), e36110817277-e36110817277.

Souza, M. L. R. (2004). Tecnologia para processamento das peles de peixe. Maringá: Eduem, 14-55.

Souza, M. L. R. D., Casaca, J. D. M., Nakaghi, L. S. O., Franco, N. D. P., Silva, L. O. D., Dourado, D. M., \& Viegas, E. M. M. (2006). Efeito da técnica de curtimento e do método utilizado para remoção da pele da tilápia-do-nilo sobre as características de resistência do couro. Revista Brasileira de Zootecnia, 35, 1273-1280.

Souza, M. L. R., Viegas, E. M. M., do Nascimento Kronka, S., Matiucci, M. A., Sbaraini, S. C., Goes, M. D., ... \& dos Reis Goes, E. S. (2021 a). Resistência do couro da tilápia em função da classificação de peso de abate e sentido de retirada do corpo de prova quando curtidos com sais de cromo. Research, Society and Development, 10(8), e33310817236-e33310817236.

Souza, M. L. R., Viegas, E. M. M., Nakaghi, L. S. O., Dourado, D. M., do Nascimento Kronka, S., \& dos Reis Goes, E. S. (2021 b). Morfologia, composição centesimal e alterações ocorridas no processo de curtimento da pele da tilápia do Nilo. Research, Society and Development, 10(8), e35810817240e35810817240. 